PACS 31.15.-p

Ternovsky E. V., Mykhailov A. L.

Odesa State Environmental University, 15, Lvovskaya str., Odesa-16, 65016, Ukraine

E-mail: ternovskyev@gmail.com

\title{
NEW RELATIVISTIC APPROACH TO COMPUTING SPECTRAL PARAMETERS OF MULTICHARGED IONS IN PLASMAS
}

\begin{abstract}
It is presented a new relativistic approach to computing the spectral parameters of multicharged ions in plasmas for different values of the plasmas screening (Debye) parameter (respectively, electron density, temperature). The approach used is based on the generalized relativistic energy approach combined with the optimized relativistic many-body perturbation theory (RMBPT) with the Dirac-Debye shielding model as zeroth approximation, adapted for application to study the spectral parameters of ions in plasmas. An electronic Hamiltonian for N-electron ion in plasmas is added by the Yukawa-type electron-electron and nuclear interaction potential. The special exchange potential as well as the electron density with dependence upon the temperature are used.
\end{abstract}

\section{Introduction}

An accurate data about spectra, radiative decay widths and probabilities, oscillator strengths, electron-collision strengths, collisional excitation and de-excitation rates for atoms and especially ions are of a great interest for different applications, namely, astrophysical analysis, laboratory, thermonuclear plasma diagnostics, fusion research, laser physics etc [1-44]. It is also very important for studying energy, spectral and radiative characteristics of a laser-produced hot and dense plasmas $[1,2,9,10]$.

Above other stimulating factors to studying electron-collisional spectroscopy of ions one should mention the X-ray laser problem, which has stimulated a great number of papers, devoted to modelling the elementary processes in laser, collisionally pumped plasma (see $[1,2]$ and Refs. therein) and construction of the first VUV and X-ray lasers with using plasma of $\mathrm{Li}-$-, Ne-like ions as an active medium. Very useful data on the Xlasers problem are firstly received and collected in the papers by Ivanova et al (see [2] and Refs. therein]. From the other side, studying spectra of ions in plasmas remains very actual in order to understand the plasma processes themselves. In most plasma environments the properties are determined by the electrons and the ions, and the interactions between them. The electron-ion collisions play a major role in the energy balance of plasmas. For this reason, modelers and diagnosticians require absolute cross sections for these processes. Cross sections for electronimpact excitation of ions are needed to interpret spectroscopic measurements and for simulations of plasmas using collisionalradiative models. At present time a considerable interest has been encapsulated to studying elementary atomic processes in plasma environments (for example, see [1,9-18] and Refs. therein) because of the plasma screening effect on the plasma-embedded atomic systems. In many papers the calculations of various atomic and ionic systems embedded in Debye plasmas have been performed [1,915]). Different theoretical methods have been employed along with the Debye screening to study plasma environments. Calculation of emission spectra of the plasma ions based in the precise theoretical techniques is practical tool, which may be used instead of very expensive sophisticated experiments. Nevertheless, there are known principal theoretical problems to be solved in order to receive the correct description of the elementary atomic processes in laser, collisionally pumped plasma. First of all, speech is about development of the advanced quantum-mechanical models for the further accurate computing oscillator strengths, electron-collisional strengths and rate coefficients for atomic ions in plasmas, including the Debye plasmas. As usually, a correct accounting for the relativ- 
istic, exchange-correlation, plasma environment effects is of a great importance. To say strictly, solving of the whole problem requires a development of the quantumelectrodynamical approach as the most consistent one to problem of the Coulomb manybody system.

In this paper, which goes on our work [1520], we present a new relativistic approach to computing the spectral parameters of multicharged ions in plasmas for different values of the plasmas screening (Debye) parameter (respectively, electron density, temperature). The approach used is based on the generalized relativistic energy approach combined with the optimized RMBPT with the DiracDebye shielding model as zeroth approximation, adapted for application to study the spectral parameters of ions in plasmas. An electronic Hamiltonian for $\mathrm{N}$-electron ion in plasmas is added by the Yukawa-type electron-electron and nuclear interaction potential. The special exchange potential as well as the electron density with dependence upon the temperature is used.

2. Optimized relativistic perturbation theory formalism for ions in plasmas

Some fundamental aspects of the approach developed were earlier presented (see, for example, Refs. [15-20]). Therefore, below we are limited only by the key and as a rule new points of a theory.

The generalized relativistic energy approach combined with the RMBPT has been in detail described in Refs. [6,24-29]. It generalizes earlier developed energy approach. The key idea is in calculating the energy shifts $\Delta E$ of degenerate states that is connected with the secular matrix $M$ diagonalization [6,24,25]. To construct $M$, one should use the Gell-Mann and Low adiabatic formula for $\Delta E$. The secular matrix elements are already complex in the PT second order. The whole calculation is reduced to calculation and diagonalization of the complex matrix $M$ and definition of matrix of the coefficients with eigen state vectors $B_{i e, i v}^{I K}[6,25]$. To calculate all necessary matrix elements one must use the bases of the 1QP relativistic functions.
Within an energy approach the total energy shift of the state is usually presented as [24]:

$$
\Delta \mathrm{E}=\operatorname{Re} \Delta \mathrm{E}+\mathrm{i} \Gamma / 2
$$

where $\Gamma$ is interpreted as the level width and decay (transition) possibility $P=\Gamma$. Let us start our consideration from formulation relativistic many-body PT with the Debye shielding model Dirac Hamiltonian for electronnuclear and electron-electron systems. Formally, a multielectron atomic systems (multielectron atom or multicharged ion) is described by the relativistic Dirac Hamiltonian (the atomic units are used) as follows:

$$
H=\sum_{i} h\left(r_{i}\right)+\sum_{i>j} V\left(r_{i} r_{j}\right) .
$$

Here, $h(r)$ is one-particle Dirac Hamiltonian for electron in a field of a nucleus and $V$ is potential of the inter-electron interaction. According to Refs. [6] it is useful to determine the interelectron potential with accounting for the retarding effect and magnetic interaction in the lowest order on parameter $\alpha^{2}$ ( $\alpha$ is the fine structure constant) as follows:

$$
V\left(r_{i} r_{j}\right)=\exp \left(i \omega_{i j} r_{i j}\right) \cdot \frac{\left(1-\alpha_{i} \alpha_{j}\right)}{r_{i j}},
$$

where $\omega_{i j}$ is the transition frequency; $\alpha_{i}, \alpha_{j}$ are the Dirac matrices.

In order to take into account the plasmas environment effects already in the PT zeroth approximation we use the known Yukawatype potential of the following form:

$$
V\left(r_{i}, r_{j}\right)=\left(Z_{a} Z_{b} \backslash r_{a}-r_{b} \mid\right) \exp \left(-\mu \cdot\left|r_{a}-r_{b}\right|\right)
$$

where $r_{a}, r_{b}$ represent respectively the spatial coordinates of particles, say, $\mathrm{A}$ and $\mathrm{B}$ and $Z_{a}$, $Z_{b}$ denote their charges.

The potential (3) is well known (look, for example, $[1,12,15]$ and Refs there) well known, for example, in the classical DebyeHückel, theory of plasmas. The plasmas environment effect is modelled by the shielding parameter $\mu$, which describes a shape of the 
long-rang potential. The parameter $\mu$ is connected with the plasma parameters such as the temperature $\theta$ and the charge density $n$ as follows:

$$
\mu \sim \sqrt{e^{2} n / k_{B} T}
$$

Here $e$ is the electron charge and $k_{B}$ is the Boltzman constant. The density $n$ is given as a sum of the electron density $N_{e}$ and the ion density $N_{\mathrm{k}}$ of the k-th ion species with the nuclear charge $q_{k}:{ }_{n}=N_{e}+\sum_{k} q_{k}^{2} N_{k}$. It is very useful to remind the simple estimates for the shielding parameter.

For example, under typical laser plasma conditions of $T \sim 1 \mathrm{keV}$ and $\mathrm{n} \sim 10^{23} \mathrm{~cm}^{-3}$ the parameter $\mu$ is of the order of 0,1 in atomic units. By introducing the Yukawa-type electron-nuclear attraction and electron-electron repulsion potentials, the Debye shielding model Dirac Hamiltonian for electronnuclear and electron-electron subsystems is given in atomic units as follows [15]:

$$
\begin{aligned}
& H=\sum_{i}\left[\alpha c p-\beta m c^{2}-Z \exp \left(-\mu r_{i}\right) / r_{i}\right]+ \\
& +\sum_{i>j} \frac{\left(1-\alpha_{i} \alpha_{j}\right)}{r_{i j}} \exp \left(-\mu r_{i j}\right)
\end{aligned}
$$

where $c$ is the velocity of light and $\mathrm{Z}$ is a charge of the atomic ion nucleus.

The formalism of the relativistic manybody PT is further constructed in the same way as the PT formalism in Refs. [16-26]. In the PT zeroth approximation one should use a mean-field potential, which includes the Yukawa-type potential (insist of the pure Coulomb one) plus exchange potential and additionally the correlation potential (for example, the Lundqvist-Gunnarson potential with the optimization parameter $b$ can be used) as in Refs. [16-18,23,24]. As alternative one could use an optimized model potential by Ivanova-Ivanov (for Ne-like ions) [6], which is calibrated within the special ab initio procedure within the relativistic energy approach $[8,16]$.
Let us concretize the corresponding meanfield potential. In particular, one of the possible versions $U(r)$ is as follows (sum of the Coulomb or Yukawa-type potential plus exchange potential:

$$
U(r)=U_{\text {Coul-Yukn }}(r)+U_{e x}(r),
$$

With the exchange potential as follows:

$$
\begin{gathered}
U_{\text {обм }}(r)= \\
\frac{4 \pi}{T} \rho(r)\left[1+6 \frac{\rho(r)}{T^{3 / 2}}+\frac{\pi^{4}}{3}\left(\frac{\rho(r)}{T^{3 / 2}}\right)^{2}\right]^{-1 / 3},
\end{gathered}
$$

where $\rho(r)$ is an electron density.

The electron density can be presented as a sum of the following terms:

$$
\begin{aligned}
& \rho(r)=\rho_{1}(r)+\rho_{2}(r), \\
& \rho_{1}(\mathrm{r}) \sim \sum_{n, l}\left|\Psi_{n l}(r)\right|^{2}
\end{aligned}
$$

$$
\begin{gathered}
\rho_{1}(r)=\frac{\sqrt{2} T^{3 / 2}}{\pi^{2}} \int \sqrt{y}\left[1+\exp \left(y-\frac{U(r)}{T}+\eta\right)\right]^{-1} d y \\
\mathrm{y}>\frac{1}{T}\left(U(r)+E_{0}\right)
\end{gathered}
$$

where $\eta=-\frac{\mu}{T}, \mu$ is a chemical potential and $E_{0}$ is a boundary between state of discrete spectrum and continuum.

The averaged numbers of fulfilling electron states can be determined on the basis of the Fermi-Dirac expression:

$$
\mathrm{N}_{\mathrm{nl}}=2(2 l+1)\left[1+\exp \left(\frac{1}{T}\left(E_{n l}+\mu\right)\right)\right]^{-1}
$$

In order to determine a chemical potential $\mu$ one should use the condition electroneutrality of the atomic corel

The point of accounting for the manybody exchange-correlation corrections within 
a presented theory can be treated as in an usual perturbation theory for free multicharged ions. As usually, in the PT second order, there are two kinds of the exchange and correlation diagrams: polarization and ladder ones. The polarization diagrams take into account the quasiparticle interaction through the polarizable core, and the ladder diagrams account for the immediate quasiparticle interaction. An effective procedure of their accounting are in details described in Refs. [6-9,20-24]. The modified PC numerical code "Superatom" is used in all calculations. Other details can be found in Refs. [1520,22,23,38].

\section{Results and conclusion}

In Tables 1 and 2 we list the numerical variations in the lifetimes of the $2 p_{1 / 2}, 3 s_{1 / 2}$, $3 p_{1 / 2}, 3 d_{3 / 2}$, and $4 s_{1 / 2}$ states in Ca XVIII for different $\mu$ values.

Table 1. The dependence of the lifetimes (ps) of the $2 \mathrm{p}_{1 / 2}$ state in the Ca XVIII spectrum upon the screening parameter $\mu$ : RCC - relativistic coupled-cluster (RCC) method [3]; This this work

\begin{tabular}{|c|c|c|}
\hline$\mu$ & $2 \mathrm{p}_{1 / 2}$ & $2 \mathrm{p}_{1 / 2}$ \\
\hline & RCC & This \\
\hline 0.133 & 741 & 740 \\
\hline 0.667 & 494 & 493 \\
\hline 1.000 & 334 & 333 \\
\hline 1.250 & 242 & 242 \\
\hline 1.429 & 192 & 191 \\
\hline 0.60 & 140 & 139 \\
\hline
\end{tabular}

Table 2.

The dependence of the lifetimes (ps) of the 3lj,4lj states in the Ca XVIII spectrum upon the parameter $\mu$ (this work)

\begin{tabular}{|c|c|c|c|c|}
\hline$\mu$ & $3 \mathrm{~s}_{1 / 2}$ & $3 \mathrm{p}_{1 / 2}$ & $3 \mathrm{~d}_{3 / 2}$ & $4 \mathrm{~s}_{1 / 2}$ \\
\hline 0.133 & 1.09 & 0.45 & 0.16 & 1.64 \\
\hline 0.667 & 1.28 & 0.54 & 0.88 & 2.56 \\
\hline 1.000 & 1.55 & 0.68 & 0.22 & 4.83 \\
\hline 1.250 & 1.87 & 0.86 & 0.28 & 12.6 \\
\hline 1.429 & 2.22 & 1.08 & 0.35 & 82.9 \\
\hline
\end{tabular}

The analysis shows that the presented data are in physically reasonable agreement with the NIST experimental data and theoretical results by relativistic coupled-cluster (RCC) method calculation [3]. However, some difference between the corresponding results can be explained by using different relativistic orbital bases and by difference in the model of accounting for the screening effect as well as some numerical differences..

\section{References}

1. Yongqiang, Li Y., Wu, J., Hou, Y., Yuan, $\mathrm{J}$. Influence of hot and dense plasmas on energy levels and oscillator strengths of ions: Be-like ions for $Z=26-36, J$. Phys. B: At. Mol. Opt. Phys. 2008, 41, 145002.

2. Saha B., Fritzsche S. Influence of dense plasma on the low-lying transitions in Belike ions: relativistic multiconfiguration Dirac-Fock calculation. J. Phys. B: At. Mol. Opt. Phys. 2007, 40, 259-270.

3. Madhulita Das, Sahoo B. K., Sourav Pal. Relativistic spectroscopy of plasma embedded Li-like systems with screening effects in two-body Debye potentials. $J$. Phys. B: At. Mol. Opt. Phys. 2014, 47, 175701.

4. Han, Y.-C., Madsen, L.B. Comparison between length and velocity gauges in quantum simulations of high-order harmonic generation Phys. Rev. A. 2010, 81, 06343.

5. Glushkov, A.V., Khetselius, O.Yu., Svinarenko, A.A., Buyadzhi, V.V., Spectroscopy of autoionization states of heavy atoms and multiply charged ions. TEC: Odessa, 2015.

6. Ivanov, L.N., Ivanova, E.P., Aglitsky, E. Modern trends in the spectroscopy of multicharged ions. Phys. Rep. 1988, 166.

7. Bandrauk, A.D., Fillion-Gourdeau, F., Lorin, E. Atoms and molecules in intense laser fields: gauge invariance of theory and models J. Phys. B: At. Mol. Opt. Phys. 2013, 46, 153001

8. Glushkov, A.V., Malinovskaya, S.V., Prepelitsa, G.P., Ignatenko, V. Manifestation 
of the new laser-electron nuclear spectral effects in the thermalized plasma: QED theory of co-operative laser-electronnuclear processes. J. Phys.: Conf. Ser. 2005, 11, 199-206.

9. Gubanova, E., Glushkov, A.V., Khetselius, O.Yu., Bunyakova, Yu.Ya., Buyadzhi, V.V., Pavlenko, E.P. New methods in analysis and project management of environmental activity: Electronic and radioactive waste. FOP: Kharkiv, 2017.

10. Glushkov, A.V., Malinovskaya, S.V., Chernyakova Y.G., Svinarenko, A.A. Cooperative laser-electron-nuclear processes: QED calculation of electron satellites spectra for multi-charged ion in laser field. I. J. Quant. Ch. 2004, 99, 889.

11. Glushkov, A., Malinovskaya, S., Loboda, A., Shpinareva, I., Gurnitskaya, E., Korchevsky, D. Diagnostics of the collisionally pumped plasma and search of the optimal plasma parameters of $\mathrm{x}$-ray lasing: calculation of electron-collision strengths and rate coefficients for Ne-like plasma. J. Phys.: Conf. Ser. 2005, 11, 188-198.

12. Glushkov, A., Ambrosov, S., Loboda, A., Gurnitskaya, E., Prepelitsa, G. Consistent QED approach to calculation of electroncollision excitation cross sections and strengths: Ne-like ions. Int. J. Quant. Chem. 2005, 104, 562-569.

13. Ignatenko, A.V. Probabilities of the radiative transitions between Stark sublevels in spectrum of atom in an DC electric field: New approach. Photoelectronics, 2007, 16, 71-74.

14. Glushkov, A.V., Ambrosov, S.V., Ignatenko, A. Non-hydrogenic atoms and Wannier-Mott excitons in a DC electric field: Photoionization, Stark effect, Resonances in ionization continuum and stochasticity. Photoelect., 2001, 10, 103.

15. Buyadzhi, V., Kuznetsova, A., Buyadzhi, A., Ternovsky, E.V., Tkach, T.B. Advanced quantum approach in radiative and collisional spectroscopy of multicharged ions in plasmas. Adv. in Quant. Chem. (Elsevier). 2019, 78, 171-191,
16. Glushkov, A., Buyadzhi, V., Svinarenko, A., Ternovsky, E. Advanced relativistic energy approach in electron-collisional spectroscopy of multicharged ions in plasma. Concepts, Methods, Applications of Quantum Systems in Chemistry and Physics (Springer). 2018, 31, 55-69.

17. Buyadzhi, V.V., Chernyakova, Yu.G., Smirnov, A.V., Tkach, T.B. Electroncollisional spectroscopy of atoms and ions in plasma: Be-like ions. Photoelectronics. 2016, 25, 97-101.

18. Buyadzhi, V.V., Chernyakova, Yu.G., Antoshkina, O.A., Tkach, T.B. Spectroscopy of multicharged ions in plasmas: Oscillator strengths of Be-like ion Fe. Photoelectronics. 2017, 26, 94.

19. Buyadzhi, V. Laser multiphoton spectroscopy of atom embedded in Debye plasmas: multiphoton resonances and transitions. Photoelectronics. 2015, 24, 128133.

20. Buyadzhi, V., Zaichko, P., Antoshkina, O., Kulakli T., Prepelitsa P., Ternovsky V., Mansarliysky, V. Computing of radiation parameters for atoms and multicharged ions within relativistic energy approach: Advanced Code. J. Phys.: Conf. Ser. 2017, 905(1), 012003.

21. Glushkov, A., Svinarenko, A., Ignatenko, A. Spectroscopy of autoionization resonances in spectra of the lanthanides atoms. Photoelectronics. 2011, 20, 90-94.

22. Glushkov, A.V. Relativistic Quantum theory. Quantum mechanics of atomic systems; Astroprint: Odessa, 2008.

23. Khetselius, O.Yu. Hyperfine structure of atomic spectra. Astroprint: Odessa, 2008.

24. Glushkov, A., Ivanov, L., Ivanova, E.P. Autoionization Phenomena in Atoms. Moscow Univ. Press, Moscow, 1986, 58.

25. Glushkov, A.V., Ivanov, L.N. Radiation decay of atomic states: atomic residue polarization and gauge noninvariant contributions. Phys. Lett.A. 1992, 170, 33.

26. Glushkov, A.V. Spectroscopy of atom and nucleus in a strong laser field: Stark effect and multiphoton resonances. J. Phys.: Conf. Ser. 2014, 548, 012020.

27. Glushkov, A., Svinarenko, A., Ternovsky, 
V., Smirnov, A., Zaichko, P. Spectroscopy of the complex autoionization resonances in spectrum of helium: Test and new spectral data. Photoelectr. 2015, 24, 94.

28. Glushkov, A.V., Ivanov, L.N. Radiation decay of atomic states: atomic residue polarization and gauge noninvariant contributions. Phys. Lett. A 1992, 170, 33.

29. Glushkov, A.V.; Ivanov, L.N. DC strongfield Stark effect: consistent quantummechanical approach. J. Phys. B: At. Mol. Opt. Phys. 1993, 26, L379-386.

30. Ivanova, E., Glushkov, A. Theoretical investigation of spectra of multicharged ions of F-like and $\mathrm{Ne}$-like isoelectronic sequences. J. Quant. Spectr. and Rad. Tr. 1986, 36(2), 127-145.

31. Ivanova, E.P., Ivanov, L.N., Glushkov, A., Kramida, A. High order corrections in the relativistic perturbation theory with the model zeroth approximation, $\mathrm{Mg}$-Like and Ne-Like Ions. Phys. Scripta 1985, 32, 513-522.

32. Glushkov, A.V. Relativistic and correlation effects in spectra of atomic systems. Astroprint, Odessa, 2006.

33. Khetselius, O.Yu. Quantum structure of electroweak interaction in heavy finite Fermi-systems. Astroprint: Odessa, 2011.

34. Khetselius, O.Yu., Lopatkin, Yu.M., Dubrovskaya, Yu.V, Svinarenko, A.A. Sensing hyperfine-structure, electroweak interaction and parity non-conservation effect in heavy atoms and nuclei: New nuclear-QED approach. Sensor Electr. and Microsyst. Techn. 2010, 7(2), 11-19.

35. Khetselius, O.Yu. Relativistic perturbation theory calculation of the hyperfine structure parameters for some heavy-element isotopes. Int. J. Quant. Chem. 2009, 109, 3330-3335.

36. Khetselius, O. Relativistic calculation of the hyperfine structure parameters for heavy elements and laser detection of heavy isotope. Phys. Scr. 2009, 135,01402

37. Svinarenko, A.A., Glushkov, A.V., Khetselius, O.Yu., Ternovsky, V.B., Dubrovskaya, Yu., Kuznetsova, A., Buyadzhi, V. Theoretical spectroscopy of rareearth elements: spectra and autoionization resonances. Rare Earth Element, Ed. J.Orjuela (InTech). 2017, 83.

38. Glushkov, A.V., Khetselius, O.Yu., Svinarenko, A.A., Buyadzhi, V.V., Ternovsky, V.B, Kuznetsova, A., Bashkarev, P Relativistic perturbation theory formalism to computing spectra and radiation characteristics: application to heavy element. Recent Studies in Perturbation Theory, InTech. 2017, 131.

39. Dubrovskaya, Yu., Khetselius, O.Yu., Vitavetskaya, L., Ternovsky, V., Serga, I. Quantum chemistry and spectroscopy of pionic atomic systems with accounting for relativistic, radiative, and strong interaction effects. Adv. Quantum Chem. 2019, 78, 193-222.

40. Khetselius, O.Yu., Glushkov, A.V., Dubrovskaya, Yu.V., Chernyakova, Yu.G., Ignatenko, A.V., Serga, I.N., Vitavetskaya, L. Relativistic quantum chemistry and spectroscopy of exotic atomic systems with accounting for strong interaction effects. In Concepts, Methods and Applications of Quantum Systems in Chem. and Phys. Springer. 2018, 31, 71.

41. Glushkov, A., Buyadzhi, V., Kvasikova, A., Ignatenko, A., Kuznetsova, A., Prepelitsa, G., Ternovsky, V. Non-Linear chaotic dynamics of quantum systems: Molecules in an electromagnetic field and laser systems. In: Tadjer A, Pavlov R, Maruani J, Brändas E, DelgadoBarrio $G$ (eds) Quantum Systems in Physics, Chemistry, and Biology. Springer, Cham. 2017, 30, 169-180.

42. Glushkov A.V., Khetselius O.Yu., Loboda A.V., Ignatenko A., Svinarenko A., Korchevsky D., Lovett L., QED Approach to Modeling Spectra of the Multicharged Ions in a Plasma: Oscillator and Electron-ion Collision Strengths.. AIP Conference Proceedings. 2008. 1058. 175-177

43. Glushkov, A.V. Atom in an electromagnetic field. KNT: Kiev, 2005.

44. Glushkov, A.V., Khetselius, O.Yu., Svinarenko, A.A., Buyadzhi, V.V., Methods of computational mathematics and mathematical physics. P.1.TES: 2015. 


\section{NEW RELATIVISTIC APPROACH TO COMPUTING SPECTRAL PARAMETERS OF MULTICHARGED IONS IN PLASMAS}

Summary. It is presented a new relativistic approach to computing the spectral parameters of multicharged ions in plasmas for different values of the plasmas screening (Debye) parameter (respectively, electron density, temperature). The approach used is based on the generalized relativistic energy approach combined with the optimized RMBPT with the DiracDebye shielding model as zeroth approximation, adapted for application to study the spectral parameters of ions in plasmas. An electronic Hamiltonian for $\mathrm{N}$-electron ion in plasmas is added by the Yukawa-type electron-electron and nuclear interaction potential. The special exchange potential as well as the electron density with dependence upon the temperature are used.

Key words: spectroscopy of ions in plasmas, relativistic energy approach, new relativistic quantum mechanical model

PACS 31.15.-p

Терновский Е.В., Михайлов А.Л.

\section{НОВЫЙ РЕЛЯТИВИСТСКИЙ ПОДХОД К РАСЧЕТУ СПЕКТРАЛЬНЫХ ПАРАМЕТРОВ МНОГОЗАРЯДНЫХ ИОНОВ В ПЛАЗМЕ}

Резюме. Представлен новый релятивистский подход к расчету спектральных параметров многозарядных ионов в плазме для различных значений параметра экранирования плазмы (дебаевского) (соответственно электронной плотности, температуры).Подход основан на обобщенном релятивистском энергетическом подходе, совмещенном с формализмом оптимизированной релятивистской многочастичной теории возмущений с приближением Дирака-Дебая в качестве нулевого приближения, адаптированной для применения при изучении спектральных параметров ионов в плазме. Электронный гамильтониан для иона $\mathrm{N}$-электронов в плазме добавляется потенциалом электрон-электронного и ядерного взаимодействия типа Юкавы. Используются специальный обменный потенциал, а также плотность электронов с фиксацией явной зависимости от температуры.

Ключевые слова: спектроскопия ионов в плазме, энергетический подход, новая релятивистская квантово-механическая модель 
Терновський С В., Михайлов О.Л.

\section{НОВИЙ РЕЛЯТИВІСТСЬКИЙ ПІДХІД ДО РОЗРАХУНКУ СПЕКТРАЛЬНИХ ПАРАМЕТРІВ БАГАТОЗАРЯДНИХ ІОНІВ В ПЛАЗМІ}

Резюме. Представлений новий релятивістський підхід до розрахунку спектральних параметрів багатозарядних іонів в плазмі для різних значень параметра екранування плазми (дебаєвсьного) (відповідно електронної щільності, температури). Підхід грунтується на узагальненому релятивістському енергетичному підході, поєднаному з формалізмом оптимізованої релятивістської багаточастинкової теорії збурень $з$ наближенням Дірака-Дебая в якості нульового наближення, адаптованого для застосування при вивченні спектральних параметрів іонів у плазмі. Електронний гамільтоніан для іона Nелектронів в плазмі додається потенціалом електрон-електронного та ядерного взаємодії типу Юкави. Використовуються спеціальний обмінний потенціал, а також щільність електронів з фіксацією явної залежності від температури.

Ключові слова: спектроскопія іонів в плазмі, енергетичний підхід, нова релятивістська квантово-механічна модель. 